\title{
Kasse muss eGK-Passbilder wieder löschen
}

\author{
Elektronische Gesundheitskarte. Im Zusammenhang mit der \\ elektronischen Gesundheitskarte (eGK) tun sich auch lange nach der \\ Einführung datenschutzrechtliche Fragen auf. Das Sozialgericht Berlin \\ hatte im vergangenen Juni in einer Entscheidung die Frage zu beur- \\ teilen, ob die zur Erstellung einer eGK eingereichten Lichtbilder von \\ den Kassen digital gespeichert werden dürfen (Urt. v. 27.06.2017, Az:: \\ S 208 KR 2111/16).
}

\section{}
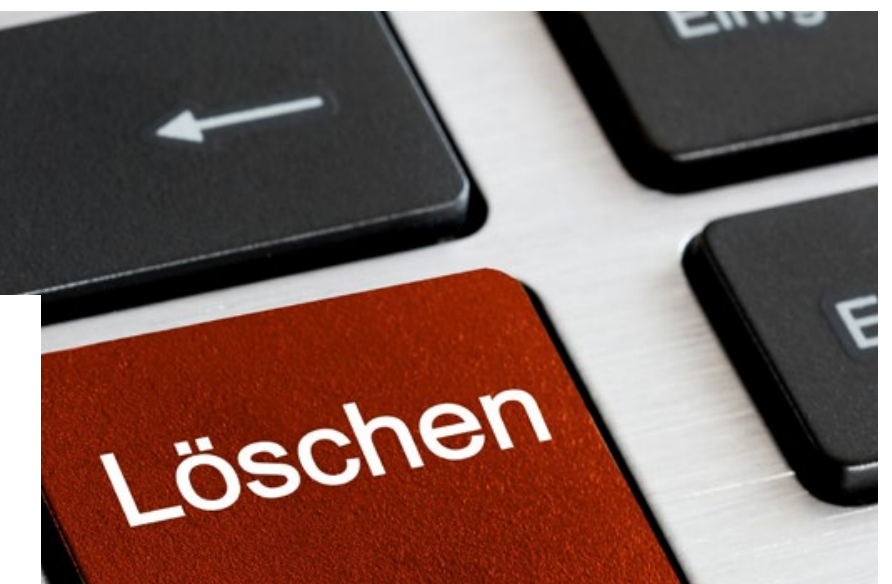